\title{
International Journal of Mechanical and Industrial Engineering
}

October 2014

\section{Comparison of Heat Transfer Performance In Domestic Refrigerator Using Nanorefrigerant And Double Pipe Heat Exchanger}

\author{
Teshome Bekele Kotu \\ School of Mechanical and Industrial Engineering Bahirdar University, Bahirdar, Ethiopia, \\ teshome_bd@yahoo.com \\ R. Reji Kumar \\ School of Mechanical and Industrial Engineering Bahirdar University, Bahirdar, Ethiopia, \\ rejikumarr2006@gmail.com
}

Follow this and additional works at: https://www.interscience.in/ijmie

Part of the Manufacturing Commons, Operations Research, Systems Engineering and Industrial Engineering Commons, and the Risk Analysis Commons

\section{Recommended Citation \\ Kotu, Teshome Bekele and Kumar, R. Reji (2014) "Comparison of Heat Transfer Performance In Domestic Refrigerator Using Nanorefrigerant And Double Pipe Heat Exchanger," International Journal of Mechanical and Industrial Engineering: Vol. 4 : Iss. 2 , Article 8.}

DOI: $10.47893 /$ JMIE.2014.1195

Available at: https://www.interscience.in/ijmie/vol4/iss2/8

This Article is brought to you for free and open access by the Interscience Journals at Interscience Research Network. It has been accepted for inclusion in International Journal of Mechanical and Industrial Engineering by an authorized editor of Interscience Research Network. For more information, please contact sritampatnaik@gmail.com. 


\title{
Comparison of Heat Transfer Performance In Domestic Refrigerator Using Nanorefrigerant And Double Pipe Heat Exchanger
}

\author{
Teshome Bekele Kotu ${ }^{[1]}$ \& R. Reji Kumar ${ }^{[2]}$ \\ ${ }^{[1],[2]}$ Lecturer, School of Mechanical and Industrial Engineering Bahirdar University, Bahirdar, Ethiopia \\ E-mail : ${ }^{[1]}$ teshome_bdu@yahoo.com, ${ }^{[2]}$ rejikumar.r2006@gmail.com
}

\begin{abstract}
Convective heat transfer is very important in the HVAC, refrigeration and microelectronics cooling applications. R134a is most widely adopted alternate refrigerant in refrigeration equipment, such as domestic refrigerators and air conditioners. Though the global warming up potential of R134a is relatively high, it is affirmed that it is a long term alternate refrigerants in lots of countries. The addition of nanoparticles to the refrigerant results in improvements in the thermophysical properties and heat transfer characteristics of the refrigerant, there by improving the performance of the refrigeration system. The performance of the domestic refrigeration system with $\mathrm{HFC134a/mineral} \mathrm{oil} \mathrm{system} \mathrm{was} \mathrm{compared} \mathrm{with} \mathrm{mineral} \mathrm{oil/nanorefrigerant} \mathrm{and} \mathrm{HFC134a/mineral}$ oil/double pipe heat exchanger. The result indicates that the system performance has improved when HFC134a/mineral oil/DPHE system was used instead of HFC134a/mineral oil and mineral oil/nano refrigerant system. The mineral oil/nano refrigerant and HFC134a/mineral oil/DPHE works normally and safely in the refrigeration system. The HFC 134a/mineral oil/DPHE system reduced the energy consumption by $30 \%$ and mineral oil/nano refrigerant system reduced the energy consumption by $26 \%$ when compared with the HFC134a/mineral oil system. There was also an enhancement in coefficient of performance (COP) when DPHE was introduced in the normal system.
\end{abstract}

Key words: Nano-refrigerant, Double pipe heat exchanger, Thermal conductivity, COP, Energy consumption..

\section{INTRODUCTION}

It is true that rapid industrialization has led to unprecedented growth, development and technological advancement across the globe. It has also given rise to several new concerns. Today global warming and ozone layer depletion on the one hand and spiraling oil prices on the other hand have become main challenges. Excessive use of fossil fuels is leading to their sharp diminution and nuclear energy is not out of harm's way. In the face of imminent energy resource crunch there is need for developing thermal systems which are energy efficient. Thermal systems like refrigerators and air conditioners consume large amount of electric power. So avenues of developing energy efficient refrigeration and air conditioning systems with nature friendly refrigerants need to be explored The rapid advances in nanotechnology have lead to emerging of new generation heat transfer fluids called nanofluids.

Most of the refrigeration system uses conventional Vapour Compression Refrigeration (VCR) cycle which has a low Co-efficient of Performance (COP).But installing a heat exchanger to the VCR makes it more efficient. The refrigerating effect of a refrigeration cycle mainly depends on the temperature of refrigerant that is entering the expansion valve. When it is compared with standard vapour compression cycle, the system using the heat exchanger will have increasing refrigerating effect as refrigerating temperature entering the expansion valve is low due to the presence of heat exchanger. Hence both the capacity and coefficient of performance will be increased. This study aims to investigate experimentally the effect of double pipe Heat Exchanger (DPHE) in a refrigeration system and compare the results.

Nanofluids are prepared by suspending nano sized particles $(1-100 \mathrm{~nm})$ in conventional fluids and have higher thermal conductivity than the base fluids. Nanofluids have the following characteristics compared to the normal solid liquid suspensions. i) higher heat transfer between the particles and fluids due to the high surface area of the particles ii) better dispersion stability with predominant Brownian motion iii) reduces particle clogging iv) reduced pumping power as compared to base fluid to obtain equivalent heat transfer. Based on the applications, nanoparticles are currently made out of a very wide variety of materials, the most common of the new generation of nanoparticles being ceramics, which are best split into metal oxide ceramics, such as titanium, zinc, aluminum and iron oxides, to name a prominent few and silicate nanoparticles, generally in the form of nanoscale flakes of clay. Addition of nanoparticles changes the boiling characteristics of the base fluids. Nanoparticles can be used in refrigeration

International Journal of Mechanical and Industrial Engineering (IJMIE), ISSN No. 2231 -6477, Volume-4, Issue-2 
systems because of its remarkable improvement in thermophysical and heat transfer capabilities to enhance the performance of refrigeration systems. In a vapour compression refrigeration system the nanoparticles can be added to the lubricant (compressor oil). When the refrigerant is circulated through the compressor it carries traces of lubricant + nanoparticles mixture (nanolubricants) so that the other parts of the system will have nanolubricant -refrigerant mixture.

\section{LITERATURE SURVAY}

Recently, some investigators have conducted studies on vapour compression refrigeration systems, to study the effect of nanoparticle in the refrigerant/lubricant on its performance.[1] Pawel et al. (2005) conducted studies on nanofluids and found that there is the significant increase in the thermal conductivity of nanofluid compared to the base fluid. They also found that addition of nanoparticles results in significant increase in the critical heat flux. [2] Bi et al. (2007) conducted studies on a domestic refrigerator using nanorefrigerants. In their studies R134a was used as a refrigerant, and a mixture of mineral oil $\mathrm{TiO} 2$ was used as the lubricant. They found that the refrigeration system with the nanorefrigerant worked normally and efficiently and the energy consumption reduces by $21.2 \%$ when compared with $\mathrm{R} 134 \mathrm{a} / \mathrm{POE}$ oil system. Later, [3] Bi et al. (2008) found that there is remarkable reduction in the power consumption and significant improvement in freezing capacity. They pointed out the improvement in the system performance is due to better thermo physical properties of mineral oil and the presence of nanoparticles in the refrigerant.

[4]Jwo et al. (2009) conducted studies on a refrigeration system replacing R-134a refrigerant and polyester lubricant with a hydrocarbon refrigerant and mineral lubricant. The mineral lubricant included added $\mathrm{Al}_{2} \mathrm{O}_{3}$ nanoparticles to improve the lubrication and heattransfer performance. Their studies show that the $60 \%$ $\mathrm{R}-134 \mathrm{a}$ and $0.1 \mathrm{wt} \% \mathrm{Al}_{2} \mathrm{O}_{3}$ nanoparticles were optimal. Under these conditions, the power consumption was reduced by about $2.4 \%$, and the coefficient of performance was increased by $4.4 \%$. [5]Peng et al. (2010) conducted experimental on the nucleate pool boiling heat transfer characteristics of refrigerant/oil mixture with diamond nano particles. The refrigerant used was R113 and the oil was VG68. They found out that the nucleate pool boiling heat transfer coefficient of R113/oil mixture with diamond nanoparticles is larger than the R113/oil mixture. They also proposed a general correlation for predicting the nucleate pool boiling heat transfer coefficient of refrigerant/oil mixture with nanoparticles, which well satisfies their experimental results.
[6]Henderson et al. (2010) conducted an experimental analysis on the flow boiling heat transfer of R134a based nanofluids in a horizontal tube. They found excellent dispersion of $\mathrm{CuO}$ nanoparticle with R134a and POE oil and the heat transfer coefficient increases more than $10 \%$ over baseline $\mathrm{R} 134 \mathrm{a} / \mathrm{POE}$ oil results.[7]Bi et al. (2011) conducted an experimental study on the performance of a domestic refrigerator using $\mathrm{TiO}_{2}-\mathrm{R} 600 \mathrm{a}$ nanorefrigerant as working fluid. They showed that the $\mathrm{TiO}_{2}-\mathrm{R} 600 \mathrm{a}$ system worked normally and efficiently in the refrigerator and an energy saving of $9.6 \%$. They too cited that the freezing velocity of nano refrigerating system was more than that with pure R600a system. The purpose of this article is to report the results obtained from the experimental studies on a vapour compression system.

Lee et al. [8] investigated the friction coefficient of the mineral oil mixed with 0.1 vol. $\%$ fullerene nanoparticles, and the results indicated that the friction coefficient decreased by $90 \%$ in comparison with raw lubricant, which lead us to the conclusion that nanoparticles can improve the efficiency and reliability of the compressor. Wang and Xie [9] found that $\mathrm{TiO}_{2}$ nanoparticles could be used as additives to enhance the solubility between mineral oil and hydrofluorocarbon (HFC) refrigerant. The refrigeration systems using the mixture of $\mathrm{R} 134 \mathrm{a}$ and mineral oil appended with nanoparticles $\mathrm{TiO}_{2}$, appeared to give better performance by returning more lubricant oil back to the compressor, and had the similar performance compared to the systems using polyol-ester (POE) and R134a. In the present study the refrigerant selected is R600a and the nanoparticle is alumina. Isobutane (R600a) is more widely adopted in domestic refrigerator because of its better environmental and energy performances. In this paper, a new refrigerator test system was built up according to the National Standard of India. A domestic $\mathrm{R} 600 \mathrm{a}$ refrigerator was selected, $\mathrm{Al}_{2} \mathrm{O}_{3}-\mathrm{R} 600 \mathrm{a}$ nanorefrigerant was prepared and used as working fluid. The energy consumption test and freeze capacity test were conducted to compare the performance of the refrigerator with nano-refrigerant and pure refrigerant so as to provide the basic data for the application of the nanoparticles in the refrigeration system.

\section{THERMOPHYSICAL PROPERTIES OF NANOFLUID.}

In order to estimate the heat transfer coefficient in the refrigerant side of the evaporator the thermophysical properties of the nanorefrigerant have to be calculated. The thermophysical properties of the nanorefrigerant are calculated in two steps. 
Firstly thermophysical properties of the nanoparticles oil mixture is calculated and this data is used to calculate the properties of nanorefrigerant.

\subsection{Calculation of thermophysical properties of nanolubricant}

The following correlations are used to calculate the thermophysical properties of nanolubricant $[10,11,12]$

Specific heat of nanolubricant

$\mathrm{Cp}_{, \mathrm{n}, \mathrm{o}}=\left(1-\psi_{\mathrm{n}}\right) \mathrm{Cp}_{\mathrm{o}}+\psi_{\mathrm{n}} \mathrm{C}_{\mathrm{pn}}$

Thermal conductivity nanolubricant,

$\mathrm{K}_{\mathrm{n}, \mathrm{o}}=\mathrm{K}_{\mathrm{o}}\left[\left(\mathrm{K}_{\mathrm{n}}+2 \mathrm{~K}_{\mathrm{o}}-2 \psi_{\mathrm{n}}\left(\mathrm{K}_{\mathrm{o}}-\mathrm{K}_{\mathrm{n}}\right)\right) /\left(\mathrm{K}_{\mathrm{n}}+2 \mathrm{~K}_{\mathrm{o}}+\psi_{\mathrm{n}}\left(\mathrm{K}_{\mathrm{o}}-\mathrm{K}_{\mathrm{n}}\right)\right)\right]$

Viscosity of nanolubricant,

$$
\mu_{n, o}=\mu_{o}\left[1 /\left(1-\psi_{n}\right) 2.5\right]
$$

Density of nanolubricant,

$$
\rho_{\mathrm{n}, \mathrm{o}}=\left(1-\psi_{\mathrm{n}}\right) \rho_{\mathrm{o}}+\psi_{\mathrm{n}} \rho_{\mathrm{n}},
$$

Volume fraction of nanoparticle in the nanoparticle-oil suspension,

$\psi_{\mathrm{n}}=\omega_{\mathrm{n}} \rho_{\mathrm{o}} /\left[\omega_{\mathrm{n}} \rho_{\mathrm{o}}+\left(1-\omega_{\mathrm{n}}\right) \rho_{\mathrm{n}}\right]$

Mass fraction in the nanoparticle oil suspension,

$\omega_{\mathrm{n}}=\mathrm{m}_{\mathrm{n}} /\left(\mathrm{m}_{\mathrm{n}}+\mathrm{m}_{\mathrm{o}}\right)$

\subsection{Calculation of thermophysical properties nanorefrigerant}

The following correlations are used to calculate the thermophysical properties of nanorefrigerant $[13,14,15]$

Specific heat of the nanorefrigerants

$\mathrm{Cp}_{\text {,r, n,o,f }}=\left(1-\mathrm{X}_{\mathrm{n}, \mathrm{o}}\right) \mathrm{Cp} \mathrm{p}, \mathrm{r}, \mathrm{f}+\mathrm{X}_{\mathrm{n}, \mathrm{o}} \mathrm{Cp} \mathrm{p}_{\mathrm{n}, \mathrm{o}}$,

Viscosity of the nanorefrigerants

$\mu \mathrm{r}, \mathrm{n}, \mathrm{o}, \mathrm{f}=\exp \left(\mathrm{Xn}, \mathrm{o} \ln \mu \mathrm{n}, \mathrm{o}+(1-\mathrm{Xn}, \mathrm{o}) \ln \mu_{\mathrm{r}, \mathrm{f}}\right),(8)$

Thermal conductivity of the nanorefrigerants

$\mathrm{K}_{\mathrm{r}, \mathrm{n}, \mathrm{f}, \mathrm{f}}=\mathrm{K}_{\mathrm{r}, \mathrm{f}}\left(1-\mathrm{X}_{\mathrm{n}, \mathrm{o}}\right)+\left(\mathrm{K}_{\mathrm{n}, \mathrm{o}} \mathrm{X}_{\mathrm{n}, \mathrm{o}}-\left(0.72 \mathrm{X}_{\mathrm{n}, \mathrm{o}}\left(1-\mathrm{X}_{\mathrm{n}, \mathrm{o}}\right)\left(\mathrm{K}_{\mathrm{n}, \mathrm{o}} \mathrm{K}_{\mathrm{r}, \mathrm{f}}\right)\right),(9)\right.$

Density of the nanorefrigerants

$\rho_{\mathrm{r}, \mathrm{n}, \mathrm{o}, \mathrm{f}}=\left[\left(\mathrm{X}_{\mathrm{n}, \mathrm{o}} / \rho_{\mathrm{n}, \mathrm{o}}\right)+\left(\left(1-\mathrm{X}_{\mathrm{n}, \mathrm{o}}\right) / \rho_{\mathrm{r}, \mathrm{f}}\right)\right]-1$

Nanoparticle/oil suspension concentration,

$\mathrm{X}_{\mathrm{n}, \mathrm{o}}=\mathrm{m}_{\mathrm{n}, \mathrm{o}} /\left(\mathrm{m}_{\mathrm{n}, \mathrm{o}}+\mathrm{m}_{\mathrm{r}}\right)$

The theoretical C.O.P is calculated using the equation C.O.P $P_{\text {th }}=(\mathrm{h} 1-\mathrm{h} 4) /(\mathrm{h} 2-\mathrm{h} 1)$

h1- enthalpy of refrigerant at the inlet of the compressor

h2 - enthalpy of refrigerant at the outlet of the compressor

$\mathrm{h} 4$ - enthalpy of refrigerant at the inlet of the evaporator
The values of the enthalpy are taken from refrigerant tables.

\section{EXPERIMENTAL SETUP AND TEST PROCEDURE}

This section provides a description of the facilities developed for conduction experimental work on a refrigerator.

\subsection{Experimental methodology}

The temperature of the refrigerant inlet/outlet of each component of the refrigerator was measured thermocouples ( $T$ type). The thermocouple sensors fitted at inlet and outlet of the compressor, condenser, and thermocouples/temperature sensors were interfaced with a HP data logger via a PC for data storage. Temperature measurement is necessary to find out the enthalpy in and out of each component of the system to, investigate the performance. The inlet and outlet pressure of refrigerant for each of the component is also necessary to find out their enthalpy at corresponding state.

The pressure transducer was fitted at the inlet and outlet of the compressor and expansion valve as shown in Fig.1. The pressure transducers were fitted with the $\mathrm{T}$-joint and then brazed with the tube to measure the pressure at desired position. The range of the pressure transducer is -1 to +39 bars. The pressure transducers also been interfaced with computer via data logger to store data.

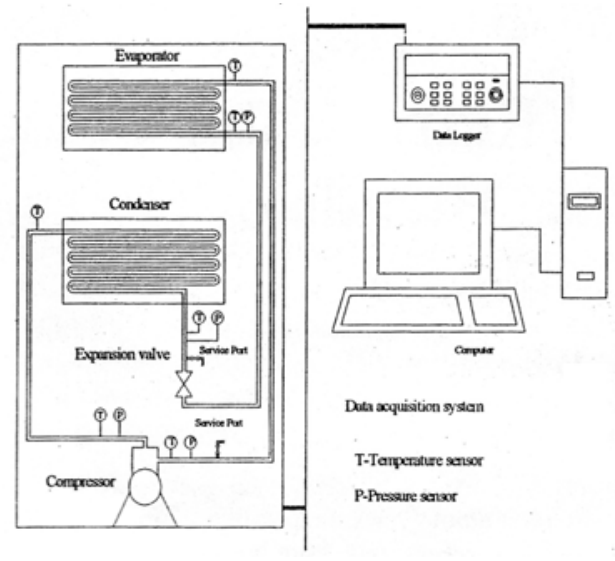

Fig. 1. Experimental apparatus

A service port was installed at the inlet of expansion valve and compressor for charging and recovering the refrigerant. The location of the service port is shown in Fig. 1. The evacuation has also been carried out through this service port. A power meter was connected with compressor to measure the power and energy consumption.

International Journal of Mechanical and Industrial Engineering (IJMIE), ISSN No. 2231 -6477, Volume-4, Issue-2 


\subsection{Preparation of nanolubricants}

Preparation of nanolubricants is the first step in the experimental studies on nanorefrigerants. Nanofluids are not simply liquid solid mixtures. Special requirements are even, stable and durable suspension, negligible agglomeration of particles, and no chemical change of the fluid. Nanofluids can be prepared using single step or two step methods. In the present study two step procedure is used. Commercially available nanoparticles of aluminium oxide (manufactured by Sigma Aldrich) with average size $<50 \mathrm{~nm}$ and having density $0.26 \mathrm{~g} / \mathrm{cc}$ were used for the preparation of nanolubricant. Mass fraction of nanoparticles in the nanoparticle-lubricant mixtures is $0.06 \%$. An ultrasonic vibrator (Micro clean 102, Oscar Ultrasonics) was used for the uniform dispersion of the nanoparticles and it took about 24 hours of agitation to achieve the same. Experimental observation shows that the stable dispersion of alumina nanoparticles can be kept for more than 3 days without coagulation or deposition.

\subsection{Test Procedure}

The system was evacuated with the help of vacuum pump to remove the moisture and charged with the help of charging system. The pressure transducers and thermocouples fitted with the system were connected with the data logger. The data logger was interfaced with the computer and software has been installed to operate the data logger from the computer and to store the data. The data logger was set to scan the data from the temperature sensor and pressure sensor at an interval of 5 minutes. A power meter was connected with the refrigerator and interfaced with the computer and power meter software was installed. The power meter stores the instantaneous power and cumulative energy consumption of the refrigerator and cumulative energy consumption of the refrigerator. The pressures and temperatures of the refrigerants from the data logger were used to determine the enthalpy of the refrigerant. All equipments and test unit was installed inside the environment control chamber where the temperature and humidity was controlled. The dehumidifier has been used to maintain desired level of humidity at the control chamber. The experiment has been conducted of the refrigeration test rig.

\section{RESULTS AND DISCUSSION}

In the present experimental study, three cases have been considered. The hermetic compressor filled with i) pure mineral oil ii) mineral oil + alumina nanoparticles as lubricant iii) mineral oil +DPHE. The mass fraction of the nanoparticles in the nanolubricant is $0.06 \%$.

\subsection{The cooling load temperature - time chart}

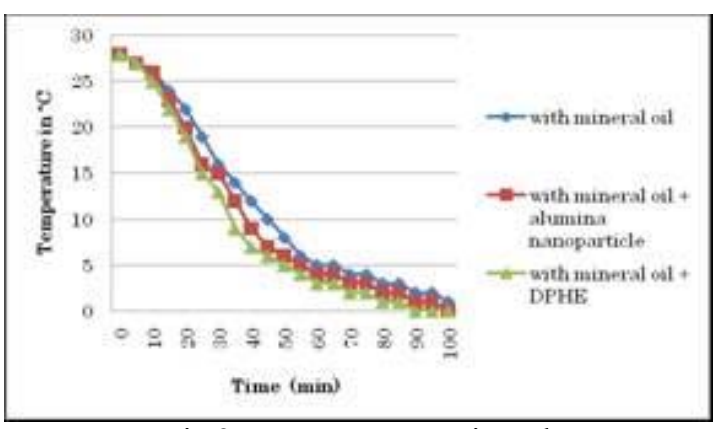

Fig.2. Temperature - Time chart

The cooling load temperature - time history is shown in figure. 2 and the freezing capacity for the three cases is shown in Figure.3. In all the cases the condenser pressure is $1.2 \mathrm{MPa}$ and the evaporator pressure is 0.2 $\mathrm{MPa}$. No appreciable pressure drops due to friction were observed in the condenser and evaporator. From the figure it is clear that, the time required for reducing cooling load temperature is less for the mineral oil + DPHE. For example, with mineral oil + DPHE, the time required to bring the cooling load temperature from $28^{\circ} \mathrm{C}$ to $5^{\circ} \mathrm{C}$ is 50 minutes where as that with mineral oil+ alumina nanoparticle and mineral oil is 55 and 60 minutes respectively. It is clear that, the freezing capacity of the mineral oil + DPHE is higher when compared with the other two cases. The time taken to reduce the temperature of the cooling load from $28^{\circ} \mathrm{C}$ to $1{ }^{\circ} \mathrm{C}$ with mineral oil is 100 minutes, reduces by $20 \%$ if mineral oil + DPHE is used and reduces by $10 \%$ if mineral oil + alumina nano particles used.

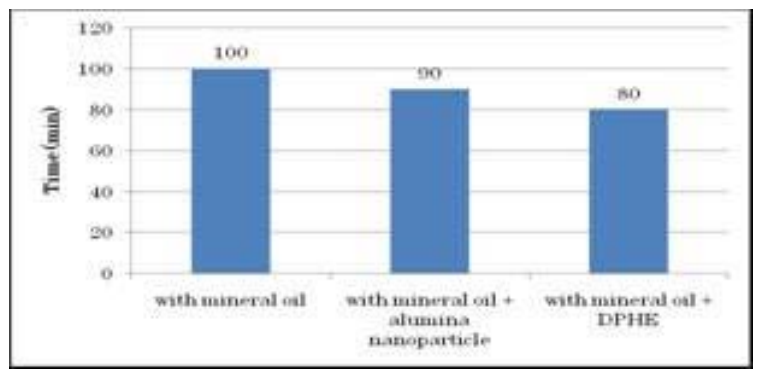

Fig.3 Effect of nanoparticle on the freezing capacity

\subsection{Reduction in refrigerant temperature while passing through the condenser}

Figure 4 shows drop in the refrigerant temperature in the condenser of the refrigeration system. Temperature drop of the refrigerant is high in DPHE and nanorefrigerant when compared with mineral oil. The temperature of the refrigerant at the inlet of the condenser is in the range $82-79^{\circ} \mathrm{C}$. The saturation

International Journal of Mechanical and Industrial Engineering (IJMIE), ISSN No. 2231 -6477, Volume-4, Issue-2 
temperature of $\mathrm{R} 134 \mathrm{a}$ corresponding to the condenser pressure of $1.2 \mathrm{MPa}$ is $46.3^{\circ} \mathrm{C}$. In the case of mineral oil nanoparticle mixture the temperature at the exit of the condenser is $38^{\circ} \mathrm{C}$ and the subcooling obtained is 8.3 ${ }^{\circ} \mathrm{C}$. In the case of mineral oil + DPHE the temperature at the exit of the condenser is $35^{\circ} \mathrm{C}$ and the subcooling obtained is $11.3{ }^{\circ} \mathrm{C}$ In fact there is no subcooling when mineral oil is used as the lubricant. The enhanced heat transfer rate in the condenser is due to the presence of nanoparticles in the refrigerant

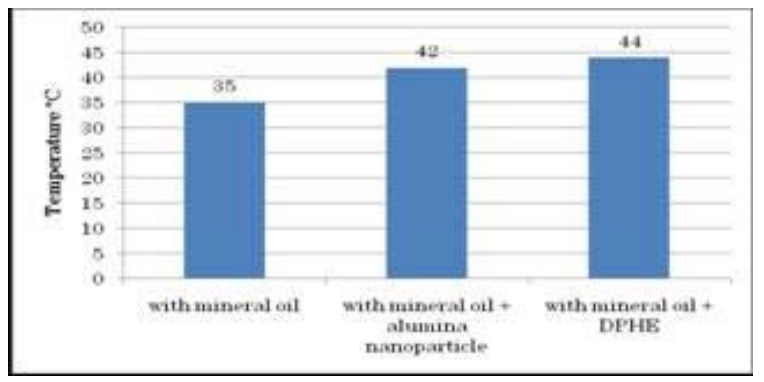

Fig.4. Reduction in refrigerant temperature while passing through the condenser

\subsection{Energy Consumption By The Compressor}

Figure 5 shows the comparison of power consumption of the compressor. The reduction in power consumption is $26 \%$ if the mineral oil with alumina nanoparticles is used instead of mineral oil and a reduction of $30 \%$ is observed when mineral oil + DPHE.

Table. 1. Energy consumption results

\begin{tabular}{|l|c|c|c|}
\hline & $\begin{array}{c}\text { R134a/M } \\
\text { ineral oil }\end{array}$ & $\begin{array}{c}\text { R134a/Mineral } \\
\text { oil with A12O3 } \\
\text { nanoparticle }\end{array}$ & $\begin{array}{c}\text { R134a/ } \\
\text { mineral } \\
\text { oil/DPHE }\end{array}$ \\
\hline $\begin{array}{l}\text { Energy } \\
\text { Consumption } \\
\text { kw hr }\end{array}$ & 0.635 & 0.470 & 0.445 \\
\hline $\begin{array}{l}\text { Energy } \\
\text { saving \% }\end{array}$ & - & 26 & 30 \\
\hline
\end{tabular}

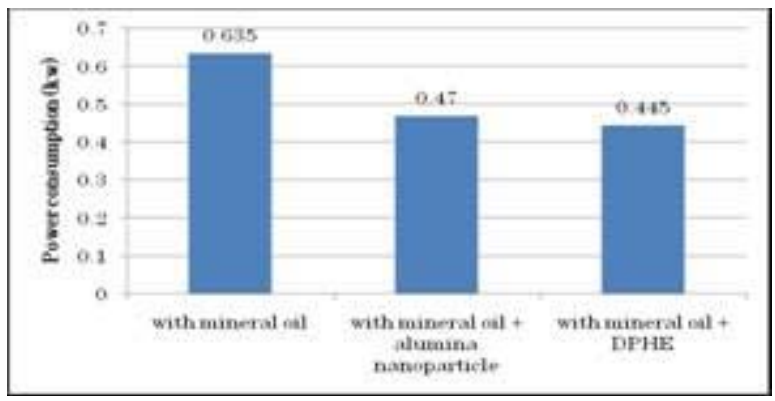

Fig.5. Comparison of power consumption

\subsection{Temperature of salient points}

Table 2. Temperature of salient points

\begin{tabular}{|l|c|c|c|}
\hline \multicolumn{1}{|c|}{ Quantity } & $\begin{array}{c}\text { R134a/ } \\
\text { Mineral } \\
\text { oil }\end{array}$ & $\begin{array}{c}\text { R134a/Miner } \\
\text { al oil with } \\
\text { Al2O3 } \\
\text { nanoparticle }\end{array}$ & $\begin{array}{c}\text { R134a/ } \\
\text { mineral } \\
\text { oil/DPHE }\end{array}$ \\
\hline $\begin{array}{l}\text { Temperature } \\
\text { at inlet of the } \\
\text { compressor }\end{array}$ & 19 & 14 & 14 \\
\hline $\begin{array}{l}\text { Temperature } \\
\text { at inlet of the } \\
\text { condenser }\end{array}$ & 82 & 80 & 79 \\
\hline $\begin{array}{l}\text { Temperature } \\
\text { at outlet of } \\
\text { the } \\
\text { condenser }\end{array}$ & 47 & 38 & 35 \\
\hline $\begin{array}{l}\text { Temperature } \\
\text { at outlet of } \\
\text { the } \\
\text { expansion } \\
\text { valve }\end{array}$ & -8 & -7 & -6 \\
\hline $\begin{array}{l}\text { Temperature } \\
\text { at inlet of the } \\
\text { evaporator }\end{array}$ & -7 & -6 & -5 \\
\hline
\end{tabular}

\subsection{Comparison of Coefficient of performance}

Figure 6 shows the coefficient of performance (COP) calculated using the experimental data. The theoretical values are also shown for comparison. The condenser pressure is $1.2 \mathrm{MPa}$ and the evaporator pressure is $0.2 \mathrm{MPa}$.. The temperatures at the salient points of the refrigeration system are shown in Table 2 . It is very much clear from the histogram shown below that the mineral oil + DPHE and mineral oil + alumina nanoparticle mixture has the highest COP when compared with mineral oil. For the calculation of theoretical COP the enthalpy values at the salient points are taken from $\mathrm{R} 134 \mathrm{a}$ refrigerant table.

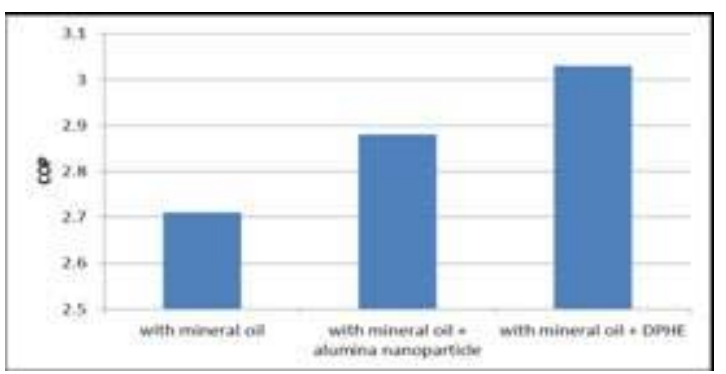

Fig. 6. Comparison of Coefficient of performance of the three cases

International Journal of Mechanical and Industrial Engineering (IJMIE), ISSN No. 2231 -6477, Volume-4, Issue-2 


\section{CONCLUSION}

The double pipe heat exchanger worked normally and efficiently with the air refrigeration system. The power consumption of the HFC134a/mineral oil/DPHE system was reduced by $30 \%$ and $\mathrm{HFC} 134 \mathrm{a} /$ mineral oil /alumina nano particle system was reduced by $26 \%$ when compared with the conventional one. The results show that the COP of HFC134a/ mineral oil/DPHE system increase by $10 \%$ and HFC134a/mineral oil/alumina nanoparticle system was increased by $6 \%$ when compared with the conventional system. Most of the refrigeration system uses conventional vapour compression refrigeration cycle which has a low coefficient of performance, but installing a double pipe heat exchanger to the VCR makes it more efficient. The refrigerating effect of a refrigeration cycle mainly depends on the temperature of the refrigerant entering the expansion valve. The refrigerating temperature entering the expansion valve was low due to the presence of heat exchanger. So when it was compared with conventional vapour compression cycle, the system using the heat exchanger had more refrigerating effect.

\section{List of symbols}

\begin{tabular}{|c|c|c|}
\hline $\begin{array}{c}\text { Symb } \\
\text { ol }\end{array}$ & Description & Unit \\
\hline \multicolumn{3}{|c|}{ Nomenclature } \\
\hline A & Cross sectional area & $\mathrm{m}^{2}$ \\
\hline $\mathrm{C}_{\mathrm{p}}$ & Specific heat & $\mathrm{J} / \mathrm{Kg} \mathrm{k}$ \\
\hline $\mathrm{h}$ & Enthalpy & $\mathrm{KJ} / \mathrm{Kg}$ \\
\hline $\mathrm{h}_{\mathrm{fg}}$ & Latent heat of vapourisation & $\mathrm{w} / \mathrm{m} \mathrm{k}$ \\
\hline $\mathrm{K}$ & Thermal conductivity & $\mathrm{w} / \mathrm{m} \mathrm{k}$ \\
\hline $\mathrm{m}$ & Mass flow rate & $\mathrm{Kg} / \mathrm{s}$ \\
\hline $\mathrm{T}$ & Temperature & ${ }^{\circ} \mathrm{C}$ \\
\hline $\mathrm{v}$ & Velocity & $\mathrm{m} / \mathrm{s}$ \\
\hline \multicolumn{3}{|c|}{ Greek symbols } \\
\hline$\sigma$ & Surface tension & $\mathrm{N} / \mathrm{m}$ \\
\hline$\rho$ & Density & $\mathrm{Kg} / \mathrm{m}^{3}$ \\
\hline$\mu$ & Dynamic viscosity & $\mathrm{Kg} / \mathrm{ms}$ \\
\hline$\omega$ & $\begin{array}{l}\text { Nanoparticle concentration in the } \\
\text { nanoparticle oil suspension }\end{array}$ & \\
\hline$\psi$ & $\begin{array}{l}\text { Volume fraction of nanoparticle } \\
\text { in the nanoparticle/oil suspension }\end{array}$ & \\
\hline \multicolumn{3}{|c|}{ Subscripts } \\
\hline $\mathrm{f}$ & liquid & \\
\hline g & gas & \\
\hline $\mathrm{n}$ & nanoparticle & \\
\hline o & oil & \\
\hline r & refrigerant & \\
\hline $\mathrm{n}, \mathrm{o}$ & nanoparticle and oil & \\
\hline $\mathrm{r}, \mathrm{o}$ & refrigerant and oil & \\
\hline $\mathrm{r}, \mathrm{n}, \mathrm{o}$ & refrigerant, nanoparticle and oil & \\
\hline
\end{tabular}

\author{
Abbreviation \\ HTC Heat Transfer Coefficient \\ TR Tonne of Refrigeration \\ COP Coefficient of Performance \\ DPHE Double Pipe Heat Exchanger
}

\section{REFERENCES}

[1] Pawel K. P., Jeffrey A.E. and David G.C., 2005. Nanofluids for thermal transport. Materials Today, pp. 36-44

[2] Bi S., Shi L. and Zhang L., 2007. Performance study of a domestic refrigerator using $\mathrm{R} 134 \mathrm{a} /$ mineral oil/nano-TiO2 as working fluid. ICR07-B2-346.

[3] Bi S., Shi L. and Zhang L., 2008. Application of nanoparticles in domestic refrigerators. Applied Thermal Engineering, Vol. 28, pp.1834-1843.

[4] Jwo et.al, 2009. Effect of nano lubricant on the performance of Hydrocarbon refrigerant system. J. Vac. Sci. Techno. B, Vol.27, No. 3, pp. 14731477.

[5] Hao Peng et.al., 2010. Nucleate pool boiling heat transfer characteristics of refrigerant/oil mixture with diamond nano particles. International Journal of Refrigeration, Vol.33, pp. 347-358.

[6] Henderson et al. (2010) Experimental analysis on the flow boiling heat transfer of R134a based nanofluids in a horizontal tube. IJHMT , Vol. 53, pp. 944-951

[7] Shengshan Bi, Performance of a Domestic Refrigerator using TiO2-R600a nano-refrigerant as working fluid, Int $\mathbf{J}$ of Energy Conservation and Management, Vol. 52, 2011, 733-737.

[8] Lee K, Hwang YJ, Cheong S, Kwon L, Kim S, Lee J. Performance evaluation of nano-lubricants of fullerene nanoparticles in refrigeration mineral oil. Curr Appl Phys 2009;9:128-31.

[9] Wang RX, Xie HB. A refrigerating system using HFC134a and mineral lubricant appended with $\mathrm{N}-\mathrm{TiO} 2(\mathrm{R})$ as working fluids. In: Proceedings of the $4^{\text {th }}$ international symposium on HAVC, Tsinghua University; 2003.

[10] Pak B.C., Cho, Y.I., 1998. Hydrodynamic and heat transfer study of dispersed fluids with submicron metallic oxide particles. Experimental Heat Transfer, Vol. 11, No. 2, pp. 151-170.

[11] Hamilton, R.L., Crosser, O.K., 1962. Thermal conductivity of heterogeneous two-component 
systems. Industrial and Engineering Chemistry Fundamentals, Vol. 1, No. 3, pp. 187-191.

[12] Brinkman, H.C., 1952. The viscosity of concentrated suspensions and solution. The Journal of Chemical Physics, Vol.20, pp. 571581.

[13] Jensen, M.K., Jackman, D.L., 1984. Prediction of nucleate pool boiling heat transfer coefficients of refrigerant-oil mixtures. Journal of Heat Transfer, Vol. 106, pp. 184-190
[14] Kedzierski, M.A., Kaul, M.P., 1993. Horizontal nucleate flow boiling heat transfer coefficient measurements and visual observations for R12, R134a, and R134a/ester lubricant mixtures. In: Proceedings of the 6th International Symposium on Transport Phenomena in Thermal Engineering, Vol. 1, pp. 111-116.

[15] Baustian, J.J., Pate, M.B., Bergles, A.E., 1988. Measuring the concentration of a flowing oilrefrigerant mixture: instrument test facility and initial results. ASHRAE Transactions, Vol. 94, No. 1, pp167-177. 